\title{
The Study of Quality of Service on a Major Mobile Network Operator in Ghana
}

\author{
"Joshua Apigagua Akanbasiam" ${ }^{1}$, Daniel Kuyoli Ngala ${ }^{2}$ \\ ${ }^{l}$ Department of Electrical and Electronics Engineering, Wa Polytechnic, Ghana. \\ ${ }^{2}$ Department of Telecommunications Engineering, Ghana Technology University College, Ghana. \\ Corresponding Author: Joshua Apigagua Akanbasiam ${ }^{l}$
}

\begin{abstract}
Quality of service is an important key performance indicator (KPI) that is used to determine how efficient an industry is in terms of services they render to their customers. In the Mobile telecommunication networks, connection quality or voice quality, retain ability and accessibility are some of the major factors used to evaluate the quality of service for customers in the industry, it is expected that maximumsatisfaction be derived for any services paid for. In this paper, a study was conducted on a major mobile network operator in Ghana(MTN). The KPIs of this network were measured, analysed and compared with the benchmark set by the local regulator (NCA) and international standard authority (ITU). It was observed that some of their KPIs values (Call Drop Rate, Bit Error Rate and Network Capacity) were within to the standard set by NCA and ITU indicating customers could experience fairly good service.
\end{abstract}

Keywords: Call Drop Rate, BER, Network Capacity, QoS.

Date of Submission: 15-10-2016

Date of acceptance: 15-07-2017

\section{Introduction}

Quality is defined as the sum of characteristics of an entity that bear on its ability to satisfy stated or implied needs [1]. The problem of Quality has gained prominence latterly especially those pertaining to services and become a fundamental way of managing any business anywhere for market growth and profitability in the service industry [2] Service consumers are demanding more from their service providers much as statutory regulatory bodies mandated to ensure standards are met in the domain within which they are mandated to regulate.The Telecom Industry being a full-fledged service oriented industry is not spared the ordeal of having to satisfy on the one hand sophisticated customer and on the other hand meet their licence agreements with their regulators. This phenomenon raises the issues of service quality in the industry. The collective effect of the performance levels of all parameters considered pertinent to a service is described as services quality. [3] The parameters for monitoring and ensuring service quality differ from the customer's and service provider's point of view, in other words Industry to Industry and Customer to Customer [3] and each of such parameters may have different priorities and performance level requirements by different segment of users [3] and regulators.

The Standards of service quality in the Telecommunication Industry is agreed upon by bodies such as the International Standard Organization (ISO), International Telecommunication Union (ITU) [3] and the respective regulatory bodies of the countries within which the service providers operate. Service quality especially as perceived by the customer or subscriber is particularly important for the service provider as this information can serve as a guide to ensure Quality Assurance (QA) and as well avoid problems with the regulators. In Ghana, with a total of six (6) mobile network operators and approximately over twenty eight million $(28,419,649)$ active subscribers, the mobile telephone industry is no doubt one of the most competitive industries in Ghana. According to December2013 Telecom Subscription report, Ghana had a total population size of 25,627,787 and a subscriber base of 28,026,482 different active mobile lines registered with the various mobile operators [4]. Mobile voice market share report as of February 2014 are as follow, $45.38 \%$ of the market share is owned by Scancom (MTN), followed by Vodafone Mobile with $22.41 \%$ and Airtel with $12.36 \%$. Millicom the operators of Tigo hold about $14.28 \%$ and Glo Mobile having about 5.02\%. Expresso controls the remaining $0.54 \%$ of the market share (Figure 1) [4]. 


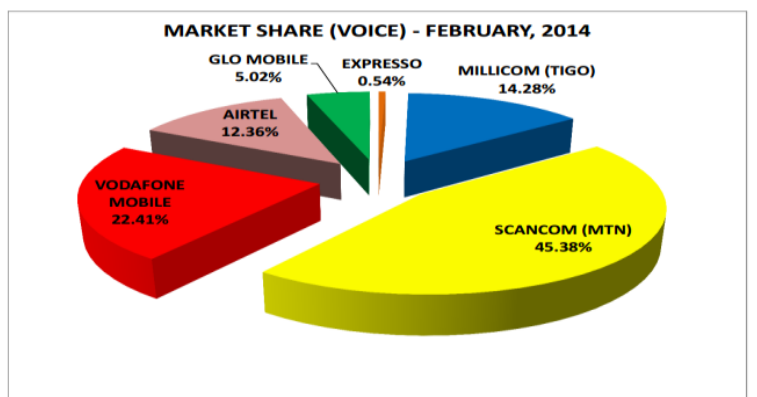

Figure 1. Mobile Network Market Share (Voice)in Ghana - February 2014 [4]

The operations of these mobile networks are being monitored by National Communication Authority (NCA) who are backed by the constitution in the National Communication Authority Act 524, 1996 in Ghana.

Table 1. NCA KPI Standards

\begin{tabular}{|l|l|}
\hline KPI & Standard(Ghana) \\
\hline SDCCH & $1 \%$ \\
\hline Call Setup Time & $<10 \mathrm{sec}$ in $95 \%$ of cases \\
\hline Voice Call Drop Rate & $3 \%$ \\
\hline Call Congestion Rate & $<1 \%$ \\
\hline
\end{tabular}

From telecom service provider's view, the factors associated with Quality of Services (QoS) also called KPIs such as Call Drop Rates (CDR), Call Setup Success Rates(CSSR),Billing Errors, Delays and Switching Errors etc. are factors that need to be monitored.

\section{Methodology}

The radio network indicators are most readily measured through the statistical performance measurement counters embedded in the base station equipment can set the performance counter to gather measurement on the live network traffic during specified time intervals and process the data through specific formulas to calculate various (KPIs). This way of measuring the KPIs offers the advantage of providing sufficient statistics without generating any test traffic on the network, and helping to trend the network performance base on the actual user traffic pattern and distribution over time and area[9]. The measurements were collected over network peak time in each area in order to best capture the effects of congestion on call blocking and interference. Data were collected from MTN Ghana Mobile Network. Care was taken when comparing different vendor's equipment as each may define the counter in different ways.

\section{Measurement Characteristics}

The method was based on three fundamental aspects:

- End-to-end measurements: measurement reflects all aspects that affect the quality of service.

- Impartiality: Measurements were carried out simultaneously for MTN in different locations, to guarantee the quality of the test condition.

- Objectivity: The tests were entirely automatic, thus eliminating the subjectivity inherent to human intervention or decision.

\section{Measurement Procedure}

The measurement profile includes process standardization to guarantee the reliability of the test and the definition of testing parameters, thus making it possible to perform analysis and compare results. The measurements were carried out in the months of December to March 2015 in Kumasi.Voice calls were performed in series of two (2) attempts with five (5) seconds for a delay of 15 seconds between series. A successful call was made to last for a maximum of 60 seconds and was made to be completed in a window of 90 seconds. The minimum time required for a call set up before the end of a call window was 30 seconds. The maximum call set up was 30 seconds. The relationship between Mobile Originating Calls (MOC) and Mobile Terminating Calls (MTC) is one is to one (1:1) [10].

\section{Tools Used for Measurements}

- GPS

- TEKRONIX M366Plus 
- $\quad$ MAPINFO

- Report Software

\section{Results And Discussion}

The data collected in the study area is hereby presented and the analysis done for all the KPIs under consideration for all the selected network operators. In order to analyse the data, mean values were determined for all the study areas and presented in a graph form.

\section{Call Set-up Success Rate (CSSR)}

This parameter measures the capability of the network to normally set up a call successfully. It is the ratio of unblocked call attempt to the total number of call attempts

CSSR $=\frac{\text { Unblockedcallattempts }}{\text { TotalNumberofCallattempts }}$

CSSR can also be expressed in (2) as

CSSR $=(1-$ ProbabilityofCallBlocking $) \times 100 \%$

The call set-up success rate (CSSR) in fig. 2, shows the fraction of the attempt to make a call that resulted in a connection to the dialled number in $2 \mathrm{G}$ and $3 \mathrm{G}$ MTN network.

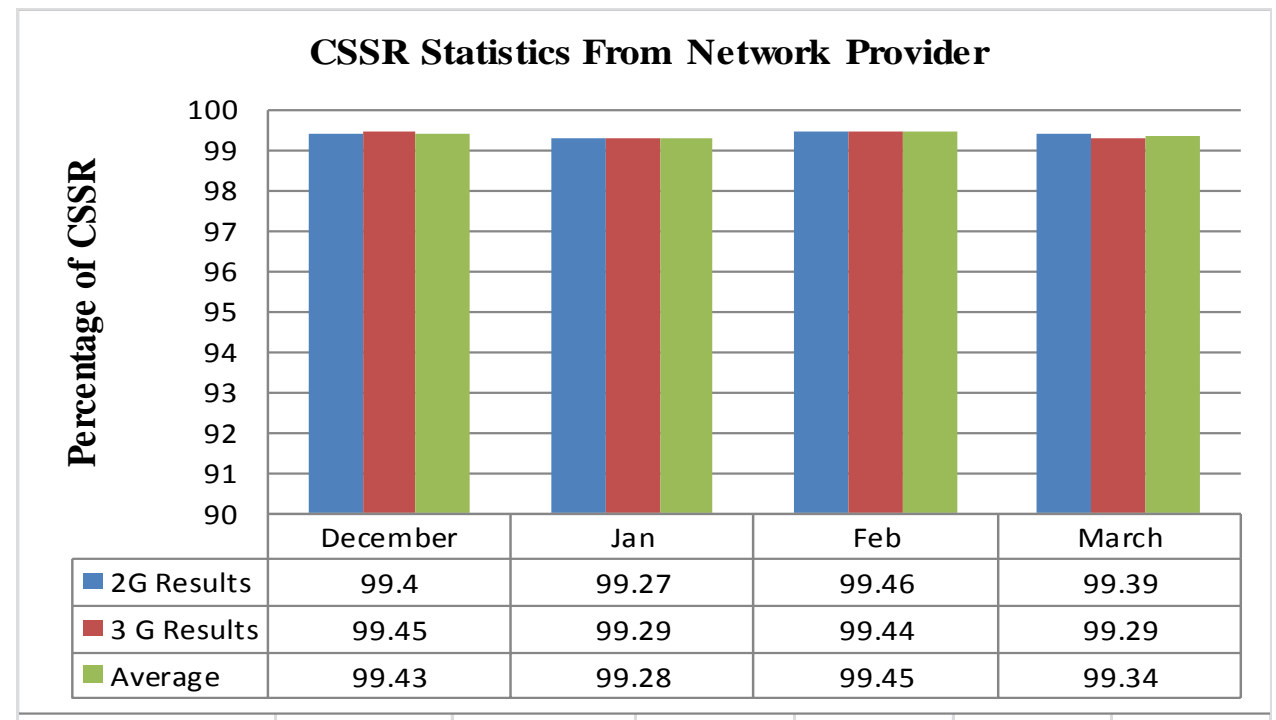

Figure 2: Call Setup Success Rate in MTN Ghana Mobile Network

It is observed from fig. 2 that, an average of $99.38 \%$ of calls generated over the Second Generation (2G) network and 99.37 of calls generated over the Third Generation $(3 \mathrm{G})$ network within the network were largely successful and acceptable in the duration of the study as compared to the benchmark set up by the local regulator (NCA) and International Standard body (ITU) that is (CSSR $>95 \%)$.

\section{Call Drop Rate (CDR)}

Drop-call probability is one of the key performance indicators (KPI) used by various mobile cellular networks operators for measuring QoS. It generally refers to the phenomenon of call/packet dropping in both voice and data networks [5]. Call/packet dropping refers to the event described as the termination of calls in progress before either involved party intentionally ends the call.

CallDropRate $(C D R)=\frac{\text { Numberof callsterminatedunwillingly }}{\text { Totalnumberof callattempts }} * 100 \%$ (3)

CDR can also be written as in (4)

$C D R=(1-$ CallCompleteProbability $) \times 100 \%$

Call drop rate should be equal or less than three percent $(3 \%)$ that is $(C D R \geq 3 \%)$. 


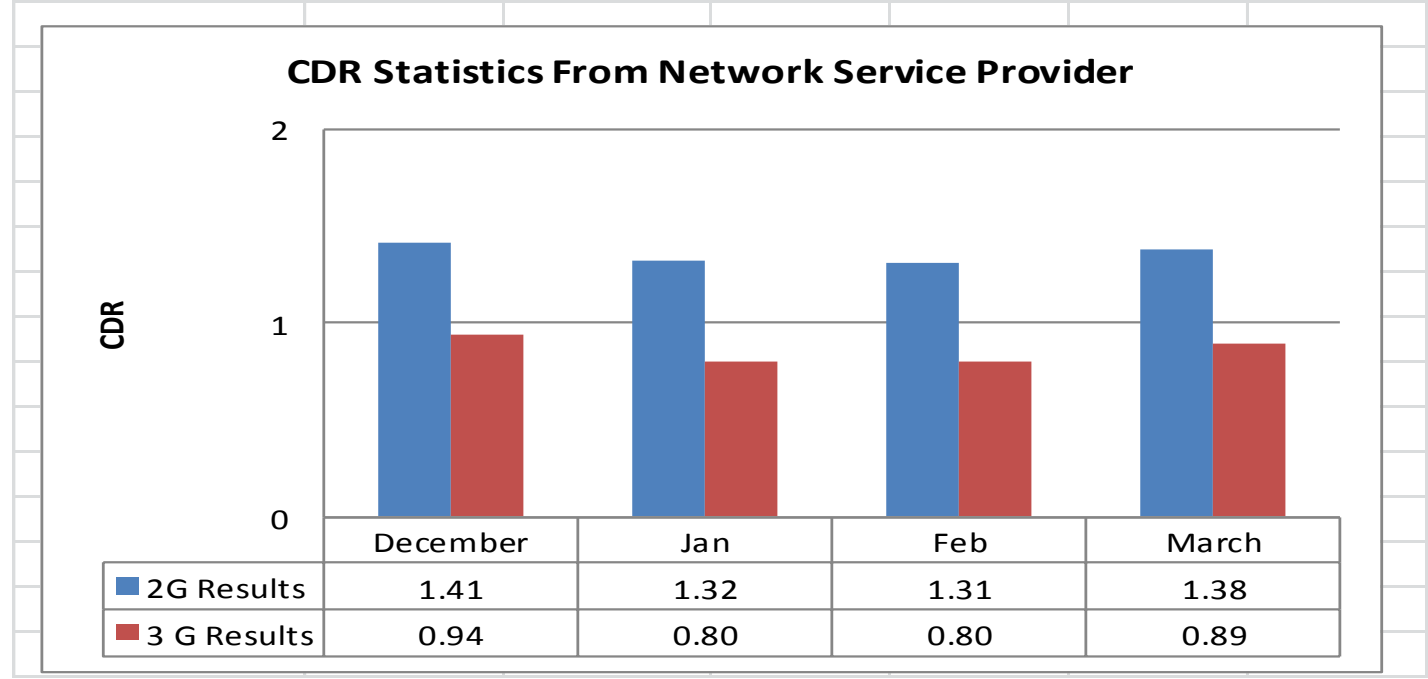

Fig. 3: Call Drop Rate for MTN mobile network in Ghana

It can be shown in Fig. 3 that at the time of the duration of this study, the results from both $3 \mathrm{G}$ and $2 \mathrm{G}$ fell within the acceptable values of the regulator $(C D R \geq 3 \%)$. Though the values recorded from the $3 \mathrm{G}$ network showed better $(C D R>1 \%)$ as compared to that of the $2 \mathrm{G}((C D R \approx 1.4 \%)$.

\section{Network Capacity}

Is the maximum traffic intensity that can be carried by network resources under given constraints on call -level in voice calls and packet-levels in data performance parameters [11]A detailed review of the network capacity statistics shows that in January, the capacity of the network increased from 60386.01 to 61193, which subsequently dropped to 60688.40 in February 2014. In March however, the capacity increased to 62509.81.

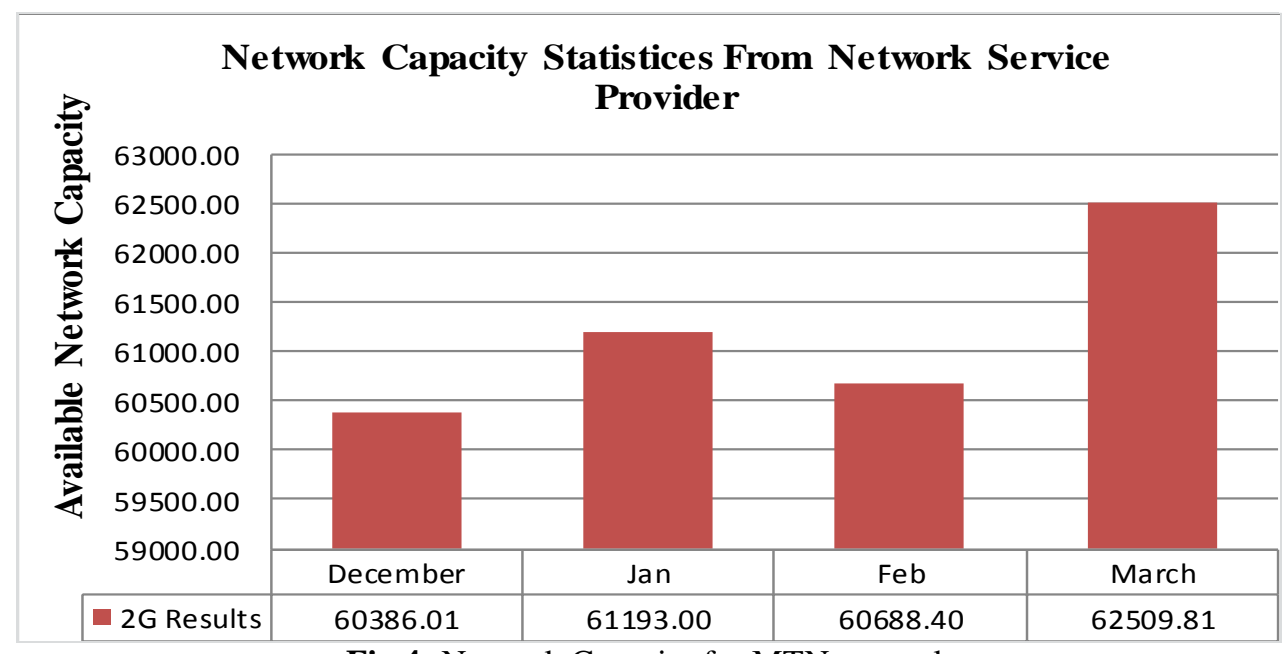

Fig 4: Network Capacity for MTN network

\section{Bit Error Rate (BER)}

The performance of mobile network can be measured in terms of BER, every network service provider has a certain level (threshold) set for BER (QoS) for which it will provide service. In the event that the BER increases above the set threshold value, this may lead to service discontinuity or poor quality of service and in the case of voice calls the network may experience call drops.Fig. 5 shows the measured BER from December to March 2015, and it can be seen that, in the month of December, the values of BER was extremely high (approximately 9.8) as compared to the other months (January to March which $\leq 3$ ). This means subscribers will experience some poor services such as call drops, poor voice quality, slow data rate etc. in the month of December because of high values of BER and improved services from January to March. 


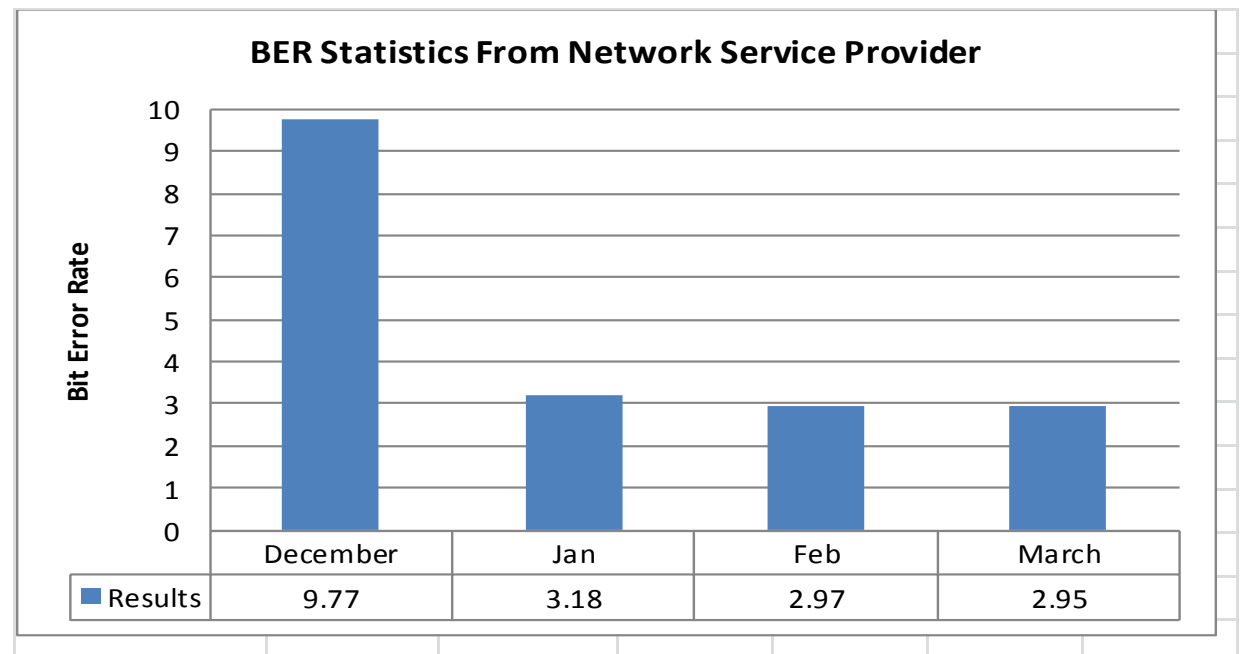

Fig. 5: Bit Error Rate (BER)

\section{Conclusion}

This study was carried out in Kumasi Metropolis on quality of service rendered by the major mobile network operator (MTN). Some KPIs such as CSSR, CDR, Network Capacity and BER were measured and a thorough analysis performed on these measurements and the outcome showed that, some of the KPIs of the Operator were below the recommended values set by regulator (NCA) and other standard bodies (ITU) while others were in agreement with the regulators and standard bodies. This means that subscribers in the areas with good KPIs will experience good services while subscribers in the areas with KPIs below recommended values will experience poor services.

\section{References}

[1] Antony, Oodan; Keith, Ward; Catherine, Savolaine; Mahmoud, Daneshmand; Peter, Hoath. (2009). Telecommunications Quality of Service Management. IET.

[2] M. N.Sinha, (2000). The Best on Quality. ASQ Quality Press.

[3] A. Oodan, (2014). Telecommunications Quality of Service Management. IET.

[4] National Communication Authority. (2014, February). Mobile Voice Market Share for February, 2014. Retrieved April 15, 2014, from http://www.nca.org.gh/downloads/Telecom_Voice_Subscription_FEB_2014_1.pdf:

http://www.nca.org.gh/downloads/Telecom_Voice_Subscription_FEB 2014_1.pdf

[5] B. L. Crgiin, "Prediction of Seasonal Trends in Cellular Dropped Call Probability", IEEE, Capital City Applied Research, Research paper, 2375 Club Miredian Dr. \#B7, Okemos, MI 48864, USA, 2006

[6] H.M., Aziz Basi, M. B. R., Murthy, "Improved Performance of Traffic Dependent Outage Rate Cellular System", Journal of Computer Science, Jan, 2005.

[7] G. Boggies. P Camarda, and A. D’Alconzo, A. De Biase, and M. Siviero, "Drop Call Probability in Established Cellular Networks from Data Analysis to Modeling”, DEE-Politecnico di Bari, Via E, Orabona, 4-70125 Bari (Italy), Proc. IEEE VTC Spring 2005, vol. 5, pp2775-2779.

[8] F. Young, "Modeling and Performance Analysis for Wireless Mobile Network: A new analytical Approach", IEEE/ACM Trans. On networking vol. 13 No. 5. Octoober 2005.

[9] A. R.Mishra, (2007). Advanced Cellular Network Planning and Optimisation: 2G/2.5G/3G...Evolution to 4G. John Wiley and Sons Ltd.

[10] QUALITY OF SERVICE. (2013). QUALITY OF SERVICE (QoS) MONITORING OF CELLULAR MOBILE VOICE SERVICES. Retrieved November 15, 2015, from http://www.nca.org.gh/downloads/QoS/QoS_Trends_04_13.pdf: http://www.nca.org.gh/downloads/QoS/QoS_Trends_04_13.pdf

[11] T. Janevski, "Traffic Analysis and Design for wireless IP Networks"(2003) ISNB 1-58053-331-0, Artech House.

\footnotetext{
Joshua Apigagua Akanbasiam. " The Study of Quality of Service on a Major Mobile Network Operator in Ghana." IOSR Journal of Electronics and Communication Engineering (IOSR-JECE) 12.4 (2017): 21 -
} 